\title{
Life-history responses to changing temperature and salinity of the Baltic Sea copepod Eurytemora affinis
}

\author{
Konrad Karlsson ${ }^{1}\left[\right.$ [D $\cdot$ Simona Puiac ${ }^{1} \cdot$ Monika Winder $^{1}$
}

Received: 6 July 2017 / Accepted: 22 December 2017 / Published online: 18 January 2018

(c) The Author(s) 2018. This article is an open access publication

\begin{abstract}
To understand the effects of predicted warming and changing salinity of marine ecosystems, it is important to have a good knowledge of species vulnerability and their capacity to adapt to environmental changes. In spring and autumn of 2014, we conducted common garden experiments to investigate how different populations of the copepod Eurytemora affinis from the Baltic Sea respond to varying temperatures and salinity conditions. Copepods were collected in the Stockholm archipelago, Bothnian Bay, and Gulf of Riga (latitude, longitude: 58 $48.19^{\prime}, 17^{\circ} 37.52^{\prime} ; 65^{\circ} 10.14^{\prime}, 23^{\circ} 14.41^{\prime} ; 58^{\circ} 21.67^{\prime}, 24^{\circ} 30.83^{\prime}$ ). Using individuals with known family structure, we investigated within population variation of the reaction norm (genotype and salinity interaction) as a means to measure adaptive capacity. Our main finding was that low salinity has a detrimental effect on development time, the additive effects of high temperature and low salinity have a negative effect on survival, and their interaction has a negative effect on hatching success. We observed no variation in survival and development within populations, and all genotypes had similar reaction norms with higher survival and faster development in higher salinities. This suggests that there is no single genotype that performs better in low salinity or high salinity; instead, the best genotype in any given salinity is best in all salinities. Genotypes with fast development time also had higher survival compared to slow developing genotypes at all salinities. Our results suggest that $E$. affinis can tolerate close to freshwater conditions also in high temperatures, but with a significant reduction in fitness.
\end{abstract}

\section{Introduction}

Climate change is affecting biodiversity of marine organisms, and particularly in coastal estuarine ecosystems like the Baltic Sea that will experience some of the greatest changes in temperature and salinity (Lehmann et al. 2011; Meier et al. 2006). To survive, grow, and reproduce under climate change, organisms have to adapt to the new environmental conditions (Davis and Shaw 2001) or migrate to new habitable areas (Parmesan 2006). Due to taxon-specific tolerance limits, it is difficult to predict how species will cope and interact with environmental changes. A good knowledge of adaptive capacity and tolerance limits of key species can

Responsible Editor: A. Atkinson.

Reviewed by Undisclosed experts.

Konrad Karlsson

konrad.karlsson@su.se

1 Department of Ecology, Environment, and Plant Sciences, Stockholm University, 10691 Stockholm, Sweden help to improve our understanding of how marine communities will reorganize because of environmental changes. Calanoid copepods are a major trophic link between primary producers and fish (Stibor et al. 2004; Tomczak et al. 2012), and highly important for maintaining fish stocks (Möllmann and Köster 2002). Consequently, it is important to understand how copepods are able to adapt to environmental changes.

Development time and reproduction are two key life-history traits that influence the population dynamics of calanoid copepods (Allan 1976). Both life-history traits are highly variable as a function of environmental conditions. Under optimal growth conditions, most of the available energy is allocated to reproduction after accounting for metabolic costs. Therefore, egg production is often used to estimate copepods optimum temperature (Hirche 1992; Holste and Peck 2006; Huntley and Lopez 1992). An increase in temperature is associated with faster development, a reduction in female's body size, and smaller egg clutches due to her smaller size (Ban 1994; Blaxter et al. 1998; Gillooly et al. 2001, 2002). Salinity is another important environmental factor affecting the distribution of copepod populations (Devreker et al. 2004; Holste and Peck 2006; Roddie et al. 
1984). Under osmotic stress, more energy is allocated for osmoregulation and less for development and egg production, which on a long temporal scale could negatively impact the recruitment potential, and the population rate of increase (Allan 1976). The ability to cope with salinities outside the optimal range is also influenced by temperature (Bradley 1986; Devreker et al. 2009; Lance 1963; Nagaraj 1988), and therefore, interactive effects of these two factors are important for assessing the response of copepod populations to abiotic change.

Eurytemora affinis (Poppe) is a euryhaline calanoid copepod with a wide distribution in the Northern hemisphere. It commonly inhabits brackish systems, often being a dominant species in zooplankton communities of European (Escaravage and Soetaert 1995; Gasparini et al. 1999; Peitsch et al. 2000) and North American (Heinle and Flemer 1975; Laprise and Dodson 1994; Winkler et al. 2003) coasts and estuaries. Despite its preference for brackish conditions, some populations of this species can be found in such diverse conditions as freshwater and hypersaline marches (Lee and Petersen 2003); therefore, tolerance limits can vary between populations, and populations demonstrate a high adaptability to salinity as a result of strong osmoregulation (Kimmel and Bradley 2001; Roddie et al. 1984).

Eurytemora affinis is an egg-carrying species and after hatching undergoes a nauplius (larval) and a copepodid (juvenile) phase before reaching adulthood (Katona 1971). The larval phase consists of six nauplius stages at the end of which the animals metamorphose into juveniles, comprising five copepodid stages, and further molt into the final adult life stage where sexual reproduction occurs. Feeding (Meunier et al. 2016), mortality (Beyrend-Dur et al. 2009), swimming behavior (Holliland et al. 2012; Schmitt et al. 2011), and predation pressure (van Someren Gréve et al. 2017) all differ between developmental stages. Consequently, the effects of environmental factors can vary between life-history stages.

The goals of the present study were to investigate how life-history traits of different $E$. affinis populations from the Baltic Sea respond to changes in temperature and salinity, and if local origin has a role in their ability to cope with environmental changes. By investigating the response of related individuals to the environment, we aim to estimate the genotype-by-environment interaction as a sign of adaptive capacity (Dam 2013). The Baltic Sea is one of the fastest warming ecosystems, and by the end of the current century, the mean sea surface temperature is predicted to increase by $2-4{ }^{\circ} \mathrm{C}$ (Lehmann et al. 2011). In addition, salinity is expected to decrease by $1.5-2$ practical salinity units (PSU) because of increasing river run-off (Meier et al. 2006). A good understanding of how E. affinis populations respond to environment conditions is highly needed to predict their capability to adapt to future climate scenarios.

\section{Materials and methods}

\section{Sampling and culture maintenance}

Copepods were collected from three different areas of the Baltic Sea along the temperature and salinity gradient using a zooplankton net with $90 \mu \mathrm{m}$ mesh size. A minimum of 300 adult $E$. affinis from each location were sorted out to establish lab cultures. One population was collected in October 2013 from the Stockholm archipelago at the Askö monitoring station B1 (STHLM) $\left(58^{\circ} 48.19^{\prime}, 17^{\circ} 37.52^{\prime}\right)$; the other two populations were collected in August and September 2014 from Pärnu Bay in the Gulf of Riga (GOR) $\left(58^{\circ} 21.67^{\prime}, 24^{\circ} 30.83^{\prime}\right)$ and monitoring station F3A5 in the Bothnian Bay (BB) $\left(65^{\circ} 10.14^{\prime}, 23^{\circ} 14.41^{\prime}\right)$. E. affinis mainly inhabit the upper $30 \mathrm{~m}$ (Holliland et al. 2012) and monthly mean salinity and temperature at this depth range differed between the locations where the populations were sampled (Fig. 1). Data were available from the Swedish Hydrological and Metrological Institute (SMHI) for station B1 and F3A5, and the International Council for the Exploration of the Seas (ICES) for Pärnu Bay (geographical cutoff: highest lat, lon $58^{\circ} 35.00^{\prime}, 24^{\circ} 47.17^{\prime}$; lowest $58^{\circ} 02.50^{\prime}, 24^{\circ} 17.17^{\prime}$ ). All available observations were used to calculate monthly means of salinity and temperature.

The lab cultures were kept in separate 101 plastic buckets at $15{ }^{\circ} \mathrm{C}$ and salinity of $6 \mathrm{PSU}$, under constant gentle aeration and a 12 1: $12 \mathrm{D}$ photoperiod. Populations were cultured

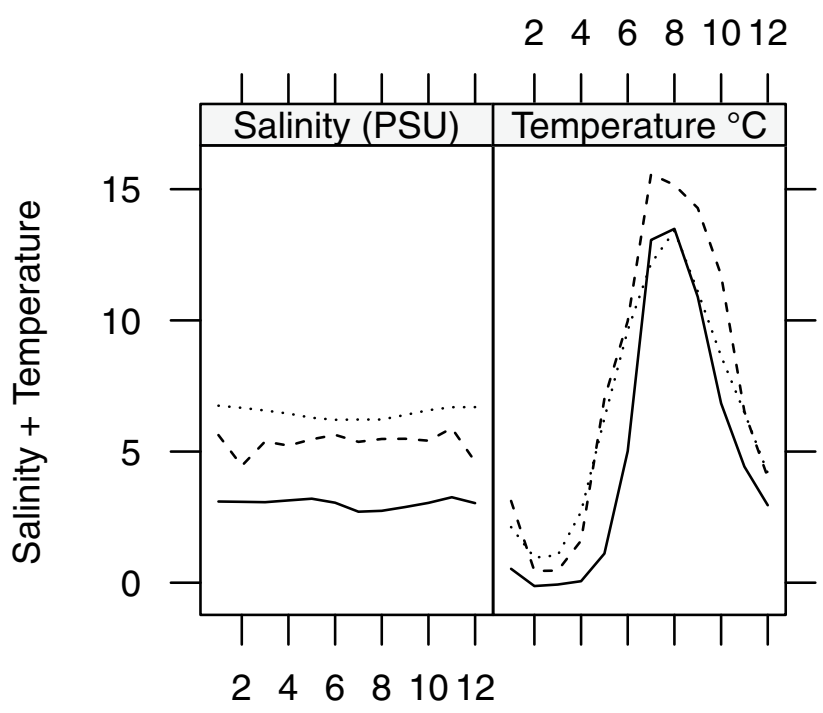

Month

Fig. 1 Monthly mean salinity (left panel) and temperature (right panel) at the sampling locations of our test populations at $\leq 30 \mathrm{~m}$ depth, the dotted line shows STHLM population, dashed shows GOR, and continuous line shows BB 
with artificial seawater, obtained by mixing Instant Ocean ${ }^{\circledR}$ sea salt with tap water. Water was changed twice a week and copepods were fed ad libitum (100,000-200,000 cells $\mathrm{ml}^{-1}$ ) with the cryptophyte algae Rhodomonas salina, cultured on an F2 media (Guillard and Ryther 1962) at 10 PSU. All populations were acclimated to the laboratory conditions for at least three generations to avoid imprints of maternal effects (Sanford and Kelly 2011).

\section{Experimental setup}

Two experimental setups were used in the present study. The first one allowed investigating temperature-salinity responses of the STHLM population, while for the GOR and $\mathrm{BB}$, only the effect of salinity was analyzed. Despite the different protocols, this provides general information on the response of E. affinis populations to temperature and salinity changes.

For the STHLM population, we used full siblings by pairing C5 female copepodites with one male; all females matured into adults in a few days and mated with the male. This procedure assured that all individuals from each female were full siblings. These pairs were put in $25 \mathrm{ml}$ glass beakers, at either $15^{\circ} \mathrm{C}$ and 2 PSU, $15^{\circ} \mathrm{C}$ and 6 PSU, $20{ }^{\circ} \mathrm{C}$ and $2 \mathrm{PSU}$, or $20^{\circ} \mathrm{C}$ and $6 \mathrm{PSU}$, we counted the number of eggs per clutch and used eggs (put in $10 \mathrm{ml}$ glass beakers) from these pairs to investigate hatching success. Once the eggs hatched, nauplii were transferred individually to $10 \mathrm{ml}$ glass beakers and development time and survival were recorded until adulthood. For the GOR and BB population, we used maternal siblings by selecting egg-carrying females from the lab cultures; for these two populations, we recorded hatching success, development time, and survival. Each female clutch was crossed over a salinity gradient $(0.5$, 5, 10 and 15 PSU) at a temperature of $22.5^{\circ} \mathrm{C}$, into two $10 \mathrm{ml}$ vials per salinity treatment. This setup allowed us to investigate if the response to salinity is different between sibling clutches (hereafter siblings is referred to as genotypes). Visual inspections of the animals were performed every day or every other day for the STHLM population, and every day for the GOR and BB populations to assess life stage and survival.

For all populations, development time and survival was assessed on three different life stages according to Katona (1971): from nauplii stage 1 to adult (hereafter adult survival/development), from nauplii stage 1 to copepodid stage 1 (hereafter nauplii survival/development), and from copepodid stage 1 to adult (hereafter copepodid survival/ development).

Replication in this study was at the level of genotype, and within each genotype, the number of individuals varied (Table 1). The use of genotype as random variable does two things: first, we avoid pseudo-replication, since individuals with the same parents are not independent. Second, in the GOR and BB population, genotypes were crossed over salinity treatments, which allowed us to quantify variation in genotypes over different salinities, which is a type of interaction between genotype and the environment (Bolker et al. 2009).

\section{Statistical analysis}

All analyses were computed in R (R Core Team 2016). We used generalized linear mixed model glmer for the analyses of clutch size, hatching success, survival, and development

Table 1 Number of genotypes (random effect) in each treatment combination in the middle columns, and the sum of observations or individuals over all treatment effects in the rightmost column and leftmost column show the separate response variables

\begin{tabular}{|c|c|c|c|c|c|}
\hline Response var. & $15^{\circ} \mathrm{C}$ and $2 \mathrm{PSU}$ & $15^{\circ} \mathrm{C}$ and $6 \mathrm{PSU}$ & $20^{\circ} \mathrm{C}$ and $2 \mathrm{PSU}$ & $20^{\circ} \mathrm{C}$ and $6 \mathrm{PSU}$ & $n$ obs./ind. \\
\hline \multicolumn{6}{|l|}{$n$ genotypes, STHLM } \\
\hline Clutch size & 10 & 10 & 13 & 9 & 139 \\
\hline Surv. adult & 8 & 5 & 8 & 10 & 356 \\
\hline Surv. cope. & 8 & 5 & 7 & 10 & 219 \\
\hline Dev. adult & 7 & 5 & 7 & 10 & 200 \\
\hline Dev. cope. & 7 & 5 & 7 & 10 & 200 \\
\hline Hatch & 9 & 5 & 8 & 8 & 1692 \\
\hline Response var. & $0.5 \mathrm{PSU}$ & $5 \mathrm{PSU}$ & 10 PSU & 15 PSU & $n$ ind. \\
\hline \multicolumn{6}{|c|}{$n$ genotypes, GOR \& BB } \\
\hline Surv. adult GOR & 9 & 9 & 9 & 9 & 190 \\
\hline Surv. cope. GOR & 9 & 9 & 9 & 9 & 121 \\
\hline Dev. adult GOR & 9 & 9 & 9 & 9 & 98 \\
\hline Dev. cope. GOR & 9 & 9 & 9 & 9 & 119 \\
\hline Hatch GOR & 9 & 9 & 9 & 9 & 368 \\
\hline Hatch BB & 6 & 6 & 6 & 6 & 178 \\
\hline
\end{tabular}


time (Bates et al. 2015). Clutch size (number of eggs) and development time (days) were analyzed as count data, whereas hatching success and survival were analyzed as proportions, i.e., hatched or not hatched and alive or dead, which is binomial data. Salinity and temperature were treated as fixed factors and genotype was treated as random effect. We also tested the influence of development time on survival; here, development time and salinity were set as fixed continuous effects and genotype as random effect. Due to low survival in the BB population, we excluded statistical tests of survival and development time analysis for this population; however, we included estimates in the figures.

To test for differences in the response of development and survival in different salinity by individual genotypes in the GOR population, we tested two generalized models (glm) against each other: one model with salinity and genotype as fixed effects (genotype + salinity) and one with main effects and their interaction (genotype + salinity + genotype $\times$ salinity) in an analysis of deviance.

For clutch size, hatching success, and survival depending on development time, mixed effect model outputs were analyzed as type two ANOVA, using the car package (Fox and Weisberg 2011). In models with non-significant interaction effect, we removed the interaction term and only analyzed main effects according to Engqvist (2005), and therefore, we do not present non-significant interaction terms in the results. Graphical outputs were made with the lattice (Sarkar 2008) and ggplot2 (Wickham 2016) packages; model estimates and confidence intervals for graphs were calculated by the effects package (Fox 2003).

\section{Results}

\section{Stockholm archipelago population}

We found the number of eggs per clutch to be unaffected by salinity $\left(d f=1, \chi^{2}=0.24, p=0.68\right)$ and temperature $(d f=1$, $\chi^{2}=1.95, p=0.16$ ), and was on average $20.89 \pm 1.03$ SE. Salinity and temperature had a significant interactive effect on hatching success $\left(d f=1, \chi^{2}=9.67, p=0.00188\right.$, Fig. 2a), indicating that the sensitivity to salinity differs between temperatures. The highest hatching success $(96 \%)$ was found at $15{ }^{\circ} \mathrm{C}$ and $6 \mathrm{PSU}$, and the lowest $(50 \%)$ at $15^{\circ} \mathrm{C}$ and 2 PSU. The effect of temperature on hatching success was not significant by itself $\left(d f=1, \chi^{2}=0.0006, p=0.981\right.$, Fig. $\left.2 \mathrm{a}\right)$, but salinity was highly significant $\left(d f=1, \chi^{2}=12.07\right.$, $p=<0.001$, Fig. 2a).

Increasing salinity and temperature shortened adult, nauplii, and copepodid development time (Table 2, Fig. 3a), and there were a tendency towards faster adult development of males than females, which was however not significant (Table 2). For adults, the effect sizes were -2.9 and -2.14 days for a respective salinity and temperature increase. The effect of temperature was greater than salinity for nauplii development ( -1.37 and -1.1 days), whereas the effect of salinity was greater for adult and copepodid development ( -1.72 and -0.85 days).

Salinity and temperature both had an effect on adult survival, which was positively affected by an increase from 2 PSU to 6 PSU and decrease from 20 to $15{ }^{\circ} \mathrm{C}$, a 30 and $20 \%$ increase, respectively (Table 3, Fig. 4a). Similarly, nauplii survival increased (23\%) with increased salinity, but there was no effect of temperature increase (Table 3, Fig. 4a), and copepodid survival was not affected by either salinity or temperature (Table 3).
Fig. 2 Hatching success in percentage as a response to salinity of a, the STHLM population at $15{ }^{\circ} \mathrm{C}$ (blue) and $20{ }^{\circ} \mathrm{C}$ (red). And $\mathbf{b}$, of the GOR (grey) and BB (black) populations. Error bars are confidence limits
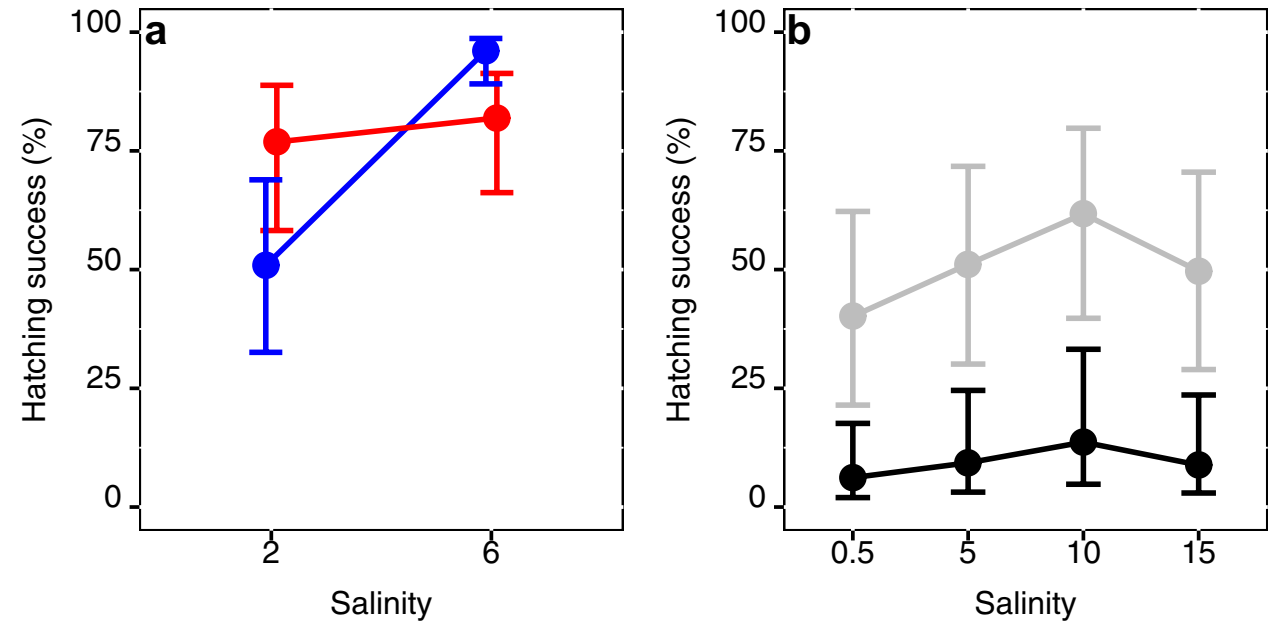
Table 2 General mixed models outcomes for different lifestage development time of the STHLM population estimates and $\mathrm{CI}$ are given in days
Fig. 3 Average copepodid (triangles) and adult (circles) development time as response to salinity of a, the STHLM population at $15^{\circ} \mathrm{C}$ (blue) and $20^{\circ} \mathrm{C}$ (red). And $\mathbf{b}$, the GOR (grey) and BB (black) population. Error bars are confidence limits

Table 3 Summary of regression outcomes of different lifestage survival for the different treatment combinations for the STHLM population

\begin{tabular}{llrrrr}
\hline Reference category & Contrast & Estimate & $95 \%$ CI & $z$ value & $p$ value \\
\hline (A) Adult development & & & & & \\
Sal. 2, Temp. 15, sex male & (Intercept) & 15.93 & $14.77,17.18$ & 71.75 & $<0.0001$ \\
& Salinity 6 & -2.90 & $12.11,14.01$ & -4.74 & $<0.0001$ \\
& Temperature 20 & -2.14 & $12.54,15.17$ & -3.57 & $<0.001$ \\
& Sex female & 1.10 & $15.71,18.47$ & 1.74 & 0.082 \\
(B) Nauplii development & & & & & \\
Sal. 2, Temp. 15, sex male & (Intercept) & 8.88 & $8.02,9.82$ & 42.30 & $<0.0001$ \\
& Salinity 6 & -1.1 & $7.06,8.55$ & -2.35 & 0.019 \\
& Temperature 20 & -1.37 & $6.61,8.53$ & -3.13 & 0.002 \\
& Sex female & 0.40 & $8.32,10.35$ & 0.87 & 0.386 \\
(C) Copepodid development & & & & & $<0.0001$ \\
Sal. 2, Temp. 15, sex male & (Intercept) & 7.17 & $6.40,8.02$ & 34.08 & $<0.0001$ \\
& Salinity 6 & -1.72 & $4.87,6.09$ & -4.28 & $<0.000$ \\
& Temperature 20 & -0.85 & $5.48,7.29$ & -2.04 & 0.042 \\
& Sex female & 0.45 & $6.74,8.60$ & 1.04 & 0.299 \\
\hline
\end{tabular}
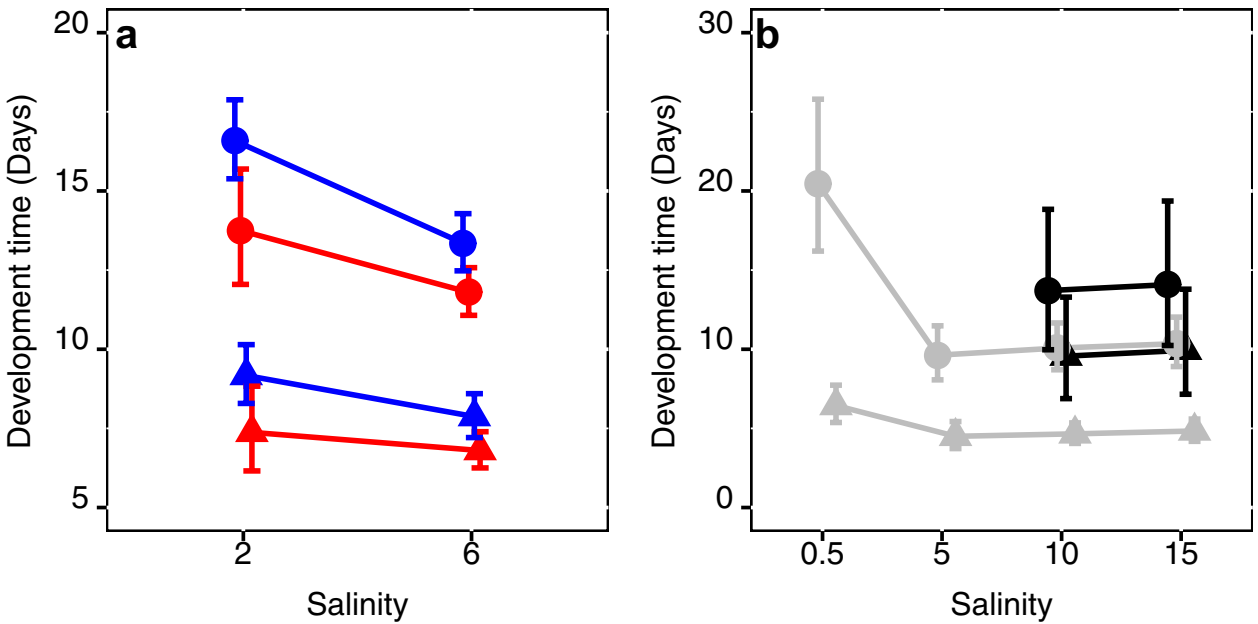

\begin{tabular}{llrrrr}
\hline Reference category & Contrast & Estimate & \multicolumn{1}{c}{$95 \%$ CI } & $z$ value & $p$ value \\
\hline (A) Adult survival & & & & & \\
Temp. 15, Sal. 2 & (Intercept) & 0.50 & $0.32,0.67$ & -0.038 & 0.969 \\
& Temperature 20 & -0.20 & $0.15,0.47$ & -2.038 & 0.042 \\
& Salinity 6 & 0.30 & $0.64,0.90$ & 3.239 & 0.001 \\
(B) Nauplii survival & & & & & \\
Temp. 15, Sal. 2 & (Intercept) & 0.58 & $0.39,0.75$ & 0.806 & 0.420 \\
& Temperature 20 & -0.16 & $0.24,0.63$ & -1.355 & 0.175 \\
& Salinity 6 & 0.23 & $0.63,0.91$ & 2.428 & 0.015 \\
(C) Copepodid survival & & & & & \\
Temp. 15, Sal. 2 & (Intercept) & 0.90 & $0.81,0.97$ & 5.013 & $<0.0001$ \\
& Temperature 20 & -0.17 & $0.55,0.89$ & -2.170 & 0.030 \\
& Salinity 6 & 0.07 & $0.94,0.99$ & 2.773 & 0.006 \\
\hline
\end{tabular}

Estimates and CI are given in proportions where 0 is no survivors and 1 is survival by all individuals 
Fig. 4 Copepodid (triangles) and adult (circles) survival in percentage as a response to salinity. For a, the STHLM population at $15{ }^{\circ} \mathrm{C}$ (blue) and $20{ }^{\circ} \mathrm{C}$ (red) and $\mathbf{b}$, the GOR population in grey and the $\mathrm{BB}$ are in black. Error bars are confidence limits
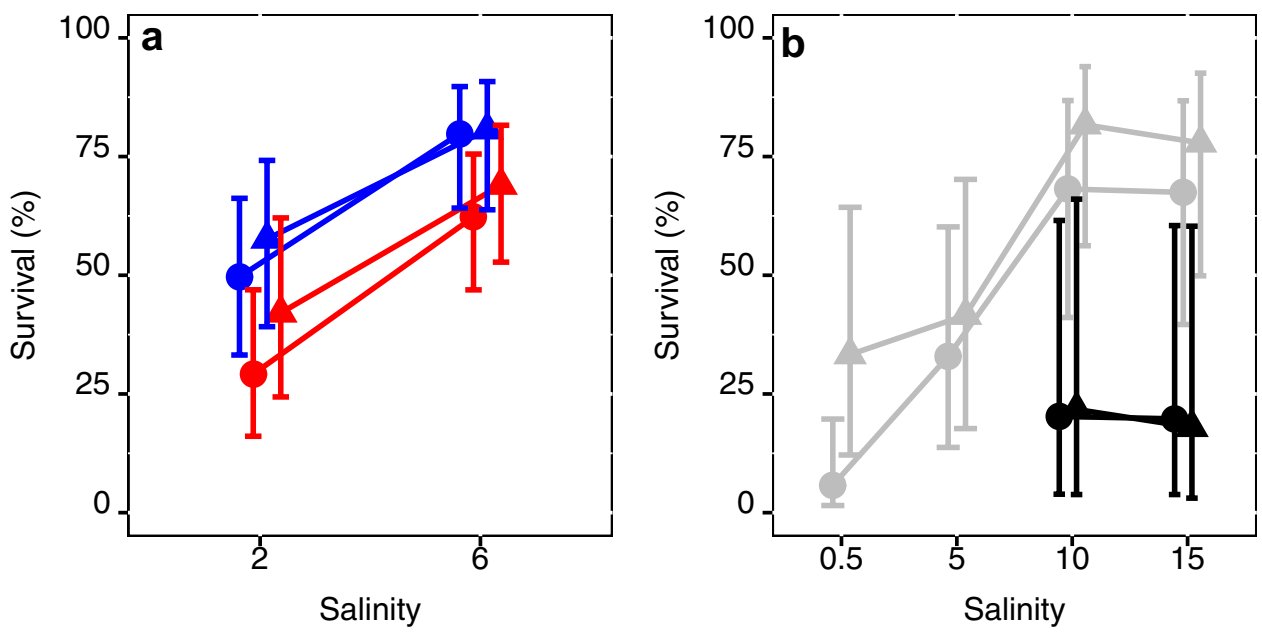

Table 4 Summary of regressions parameters of development time across salinity treatments for the GOR population from general mixed model outcomes, estimates, and $\mathrm{CI}$ is given in days

\begin{tabular}{|c|c|c|c|c|c|}
\hline Reference & Contrast & Estimate & $95 \% \mathrm{CI}$ & $t$ value & $p$ value \\
\hline \multicolumn{6}{|c|}{ (A) Adult development } \\
\hline \multirow[t]{4}{*}{ Salinity 0.5} & (Intercept) & 20.49 & $16.21,26.07$ & 25.26 & $<0.0001$ \\
\hline & Salinity 5 & -10.85 & $8.05,11.65$ & -6.08 & $<0.0001$ \\
\hline & Salinity 10 & -10.44 & $8.54,11.80$ & -6.04 & $<0.0001$ \\
\hline & Salinity 15 & -10.12 & $8.83,12.26$ & -5.89 & $<0.0001$ \\
\hline \multirow[t]{3}{*}{ Salinity 5} & (Intercept) & 9.63 & $8.05,11.65$ & 24.87 & $<0.0001$ \\
\hline & Salinity 10 & 0.42 & $8.54,11.80$ & 0.46 & 0.646 \\
\hline & Salinity 15 & 0.74 & $8.83,12.26$ & 0.80 & 0.426 \\
\hline \multirow[t]{2}{*}{ Salinity 10} & (Intercept) & 10.06 & $8.54,11.80$ & 30.13 & $<0.0001$ \\
\hline & Salinity 15 & 0.32 & $8.83,12.26$ & 0.40 & 0.693 \\
\hline \multicolumn{6}{|c|}{ (B) Nauplii development } \\
\hline \multirow[t]{4}{*}{ Salinity 0.5} & (Intercept) & 6.44 & $5.34,8.03$ & 20.07 & $<0.0001$ \\
\hline & Salinity 5 & -1.94 & $3.70,5.46$ & -2.69 & 0.007 \\
\hline & Salinity 10 & -1.76 & $4.05,5.40$ & -2.72 & 0.007 \\
\hline & Salinity 15 & -1.64 & $4.12,5.64$ & -2.45 & 0.015 \\
\hline \multirow[t]{3}{*}{ Salinity 5} & (Intercept) & 4.50 & $3.70,5.46$ & 15.63 & $<0.0001$ \\
\hline & Salinity 10 & 0.18 & $4.05,5.40$ & 0.33 & 0.740 \\
\hline & Salinity 15 & 0.31 & $4.12,5.64$ & 0.54 & 0.592 \\
\hline \multirow[t]{2}{*}{ Salinity 10} & (Intercept) & 4.68 & $4.05,5.40$ & 21.39 & $<0.0001$ \\
\hline & Salinity 15 & 0.12 & $4.12,5.64$ & 0.25 & 0.805 \\
\hline \multicolumn{6}{|c|}{ (C) Copepodid development } \\
\hline \multirow[t]{4}{*}{ Salinity 0.5} & (Intercept) & 13.79 & $10.29,18.68$ & 17.51 & $<0.0001$ \\
\hline & Salinity 5 & -8.66 & $4.03,6.57$ & -6.18 & $<0.0001$ \\
\hline & Salinity 10 & -8.49 & $4.27,6.49$ & -6.28 & $<0.0001$ \\
\hline & Salinity 15 & -8.28 & $4.47,6.85$ & -6.22 & $<0.0001$ \\
\hline \multirow[t]{3}{*}{ Salinity 5} & (Intercept) & 5.12 & $4.03,6.57$ & 13.56 & $<0.0001$ \\
\hline & Salinity 10 & 0.16 & $4.27,6.49$ & 0.25 & 0.801 \\
\hline & Salinity 15 & 0.38 & $4.47,6.85$ & 0.57 & 0.572 \\
\hline \multirow[t]{2}{*}{ Salinity 10} & (Intercept) & 5.29 & $4.27,6.49$ & 16.72 & $<0.0001$ \\
\hline & Salinity 15 & 0.21 & $4.47,6.85$ & 0.36 & 0.716 \\
\hline
\end{tabular}


Fig. 5 Response to salinity of the separate genotypes from the GOR population, a show adult development time, where points are development time per individual, and $\mathbf{b}$ show adult survival where points are average survival per vial. Color coding is the same in both panels; points show every genotype, while lines show the genotypes that have estimates across salinity

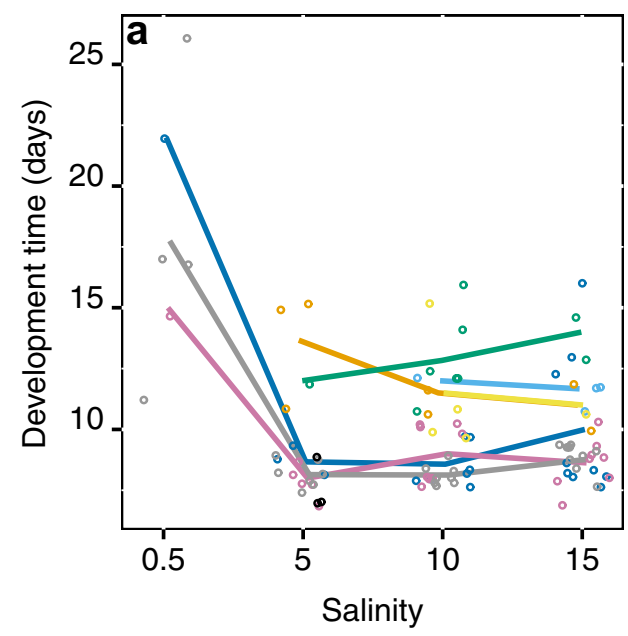

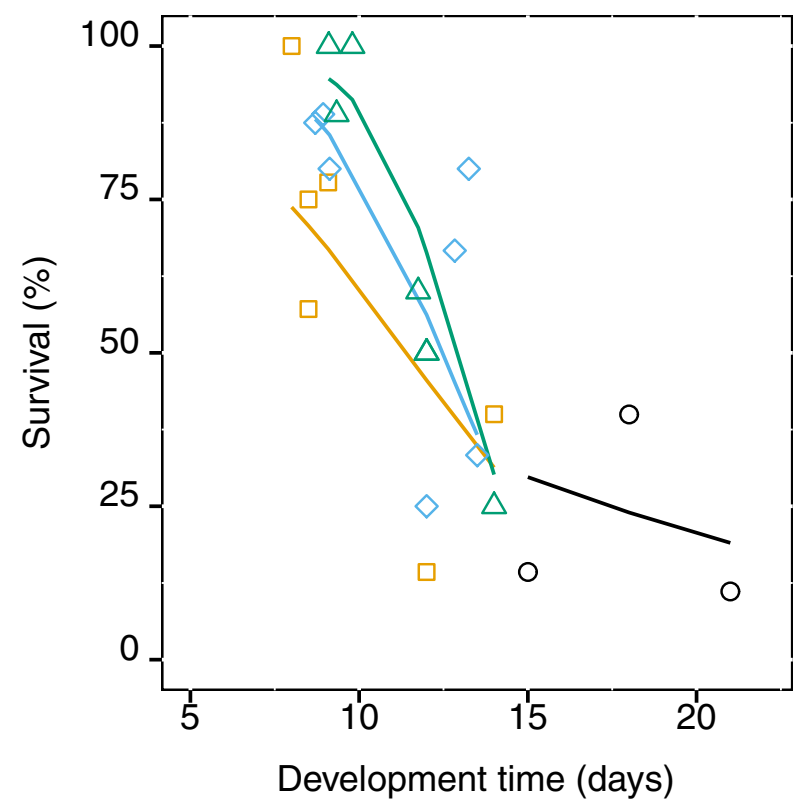

Fig. 6 Average adult survival as a response to average adult development time in different salinities for the GOR population. Lines represent fitted values and points are observed values; the different colors are: black 0.5 , orange 5 , blue 10 , and green $15 \mathrm{PSU}$

\section{Gulf of Riga and Bothnian Bay populations}

We found a weak significant effect of salinity on hatching success ( $d f=3, \chi^{2}=7.91, p=0.0479$, Fig. 2b), an average increase of $0.5 \% \mathrm{PSU}^{-1}$, and the intercept at $0.5 \mathrm{PSU}$ for hatching success which was higher for the GOR population than for the BB population, 40 and $6 \%$, respectively $(d f=1$, $\chi^{2}=11.08, p<0.001$, Fig. 2b).

Adult, nauplii, and copepodid development were longer at 0.5 PSU compared to the higher salinities of 5, 10, and 15 , while there was no difference between the salinities from 5 and above (Table 4, Fig. 3b), and was 10.85, 1.94, and
8.66 days shorter in 5 than in 0.5 PSU for adult, nauplii, and copepodid development, respectively.

Genotype-by-salinity interaction was not significant for both adult development $\left(d f=12, \chi^{2}=3.13, p=0.514\right.$, Fig. 5a) and adult survival $\left(d f=22, \chi^{2}=25.81, p=0.259\right.$, Fig. 5b), and thus, the response to salinity was similar across genotypes, and the "best" genotype in one salinity was also best in all salinities.

On genotype level, development time had a strong effect on adult survival $\left(d f=1, \chi^{2}=17.04, p=<0.0001\right)$, and there was no main effect of salinity $\left(d f=1, \chi^{2}=0.84\right.$, $p=0.361$ ), but we found a significant interaction of salinity and development time $\left(d f=1, \chi^{2}=9.04, p=0.00264\right)$. Thus, the faster the genotype develop, the more likely they are to survive, particularly in salinities from 5 PSU and above, while in lower salinity, the effect of development time decreases (Fig. 6).

Survival to adult was significantly lower in $0.5 \mathrm{PSU}(6 \%)$ compared to the higher salinities 5 (34\%), 10 (66\%), and 15 PSU (67\%), and lower in 5 PSU than in 10 and 15 PSU, with no difference between the two later salinities (Table 5, Fig. 4b). For nauplii, survival was significantly lower in 0.5 and 5 PSU compared to 10 and 15 PSU (Table 5), and copepodid survival differed only between 0.5 and the higher salinities 5, 10 and 15 PSU (Table 5, Fig. 4b).

\section{Discussion}

Our study reveals how clutch size, hatching success, development time, and survival are affected by changing temperature, salinity, and their interactions in different populations of the calanoid copepod E. affinis sampled along the Baltic Sea salinity and temperature gradient. In general, our results revealed that lower salinity than ambient has detrimental effects for all population, whereas higher salinity 
Table 5 Summary of regression outcomes of different life-stage survival for the GOR population

\begin{tabular}{|c|c|c|c|c|c|}
\hline Reference category & Contrast & Estimate & $95 \% \mathrm{CI}$ & $z$ value & $p$ value \\
\hline \multicolumn{6}{|l|}{ (A) Adult survival } \\
\hline \multirow[t]{4}{*}{ Salinity 0.5} & (Intercept) & 0.06 & $0.01,0.19$ & -3.924 & $<0.0001$ \\
\hline & Salinity 5 & 0.28 & $0.12,0.62$ & 3.436 & $<0.001$ \\
\hline & Salinity 10 & 0.61 & $0.37,0.88$ & 5.410 & $<0.0001$ \\
\hline & Salinity 15 & 0.62 & $0.36,0.88$ & 5.369 & $<0.0001$ \\
\hline \multirow[t]{3}{*}{ Salinity 5} & (Intercept) & 0.34 & $0.12,0.62$ & -1.178 & 0.239 \\
\hline & Salinity 10 & 0.34 & $0.37,0.88$ & 2.796 & 0.005 \\
\hline & Salinity 15 & 0.34 & $0.36,0.88$ & 2.741 & 0.006 \\
\hline \multirow[t]{2}{*}{ Salinity 10} & (Intercept) & 0.67 & $0.37,0.88$ & 1.241 & 0.214 \\
\hline & Salinity 15 & 0.00 & $0.36,0.88$ & 0.036 & 0.972 \\
\hline \multicolumn{6}{|l|}{ (B) Nauplii survival } \\
\hline \multirow[t]{4}{*}{ Salinity 0.5} & (Intercept) & 0.33 & $0.11,0.65$ & -1.053 & 0.292 \\
\hline & Salinity 5 & 0.09 & $0.16,0.73$ & 0.707 & 0.479 \\
\hline & Salinity 10 & 0.48 & $0.54,0.95$ & 3.612 & $<0.001$ \\
\hline & Salinity 15 & 0.44 & $0.48,0.94$ & 3.234 & 0.001 \\
\hline \multirow[t]{3}{*}{ Salinity 5} & (Intercept) & 0.42 & $0.16,0.73$ & -0.505 & 0.614 \\
\hline & Salinity 10 & 0.39 & $0.54,0.95$ & 3.257 & 0.001 \\
\hline & Salinity 15 & 0.35 & $0.48,0.94$ & 2.824 & 0.005 \\
\hline \multirow[t]{2}{*}{ Salinity 10} & (Intercept) & 0.81 & $0.54,0.95$ & 2.261 & 0.024 \\
\hline & Salinity 15 & -0.03 & $0.48,0.94$ & -0.358 & 0.721 \\
\hline \multicolumn{6}{|c|}{ (C) Copepodid survival } \\
\hline \multirow[t]{4}{*}{ Salinity 0.5} & (Intercept) & 0.23 & $0.05,0.48$ & -1.681 & 0.093 \\
\hline & Salinity 5 & 0.63 & $0.63,0.97$ & 3.411 & $<0.001$ \\
\hline & Salinity 10 & 0.65 & $0.73,0.96$ & 3.681 & $<0.001$ \\
\hline & Salinity 15 & 0.69 & $0.77,0.98$ & 3.937 & $<0.0001$ \\
\hline \multirow[t]{3}{*}{ Salinity 5} & (Intercept) & 0.86 & $0.63,0.97$ & 2.761 & 0.006 \\
\hline & Salinity 10 & 0.02 & $0.73,0.96$ & 0.210 & 0.834 \\
\hline & Salinity 15 & 0.05 & $0.77,0.98$ & 0.629 & 0.530 \\
\hline \multirow[t]{2}{*}{ Salinity 10} & (Intercept) & 0.88 & $0.73,0.96$ & 3.845 & $<0.001$ \\
\hline & Salinity 15 & 0.03 & $0.77,0.98$ & 0.493 & 0.622 \\
\hline
\end{tabular}

Estimates and CI are given in proportions where 0 is no survivors and 1 is survival by all individuals than ambient has weak positive or no effects on life-history traits. Higher temperature decreased development time substantially and had a comparable weaker negative effect on copepod survival than salinity.

Clutch size in the STHLM population was unaffected by both salinity and temperature. Commonly, for calanoid copepods, larger females have more eggs, and females grow larger in colder temperatures (Gillooly et al. 2001; Horne et al. 2016; Mclaren 1963). The lack of clutch size differences at the temperature range used in our experiment could be due to a stationary phase at the temperature interval from 15 to $20^{\circ} \mathrm{C}$. For E. affinis in the Schlei Fjord (southwestern Baltic Sea), egg number and prosome size decreased with increasing temperature throughout the spring and summer (Hirche 1992). Furthermore, Hirche (1992) showed that body size and egg number follow similar fitted curves, where size and egg numbers are stationary at some temperature intervals and have inflection points at others. An opposite clutch size-temperature relation was found in an E. affinis population from the Seine estuary, which had larger mean clutch size at $15^{\circ} \mathrm{C}$ than at $10{ }^{\circ} \mathrm{C}$ (Devreker et al. 2009). This suggests that clutch size and temperature reaction norm is population specific for E. affinis.

Our results showed that hatching success increase more with salinity at low temperature than at high for the STHLM population (Fig. 2a), and salinity increase had a strong positive effect on hatching success. For the GOR and BB populations, there was only a weak positive effect of salinity on hatching success, even though much lower and higher salinities than ambient were used (eight times as low and three times as high for the GOR population, and four times as low and five times as high for the BB population). Our hatching success results from Baltic Sea $E$. affinis are not in agreement with other studies of brackish water populations of E. affinis that found hatching success to be at large 
unaffected by temperature and/or salinity (Beyrend-Dur et al. 2009; Devreker et al. 2009; Diekmann et al. 2012; Lee and Petersen 2002). However, Lee et al. (2003) found a freshwater population to have lower hatching success as salinity increased. Our results suggests that lower salinity than ambient have negative effects on hatching success for E. affinis in the Baltic Sea. However, this likely depends on population origin and the population from the highest salinity (STHLM; Fig. 1a) showed the most negative response, but the effect is also temperature-dependent and salinity changes have larger effect at lower temperature $\left(15^{\circ} \mathrm{C}\right)$.

Development time is an important fitness trait in zooplankton, and intimately connected to generation time and population rate of increase, with faster development leading to higher abundances in shorter time (Allan 1976). Thus, fast developing populations will have a competitive advantage over slower developing ones, if all other possible parameters are equal. Evidence suggests that that fast development at higher temperatures tends to lead to smaller females with smaller clutch size than at lower temperatures (Mclaren 1963). However, for the calanoid copepod Acartia hudsonica, Avery and Dam (2007) found that the daily egg production rate increases with decreasing development time, which suggests that daily egg production will increase with increasing temperature. In zooplankton, temperature is a master factor, and increasing temperature both increases metabolism and decreases development time (Devreker et al. 2007; Gillooly et al. 2001, 2002; Vuorinen 1982). In the present study, both temperature and salinity for the STHLM population and salinity for the GOR population affected development time for all life stages. Decreasing salinity slows down development and increasing temperature speeds up development. Interestingly for the STHLM population, the magnitude of temperature and salinity effects differs between life stages. For adult and copepodid development, higher salinity decreased development time more than higher temperature. In contrast, for nauplii development, time temperature had a larger effect than salinity (Table 2, Fig. 3a). This suggests that early life stages are less affected by low salinity but more affected by high temperature compared to later life stages.

The genotype and salinity interaction is a measure of the individual genotypes' response to salinity; with a non-significant result, we can infer a homogenous response to salinity, whereas with a significant interaction, we can infer a heterogenous response to salinity (Falconer and Mackay 1996). The interactive variation where one genotype is better in low salinity and another in high salinity implies genetic variation in the reaction norm, and a basis for selection by salinity to change the population's mean reaction norm (Dam 2013; Lee et al. 2007). In contrast, we found no significant interaction for adult development and survival (Fig. 5a, b), and thus, there is a little variation between genotypes in their response to development and survival in different salinities. This emphasizes that the difficulty Baltic Sea E. affinis have with decreased salinity. Despite this, some genotypes perform better than others do, with faster development and higher survival in all salinities (Fig. 6). Selection by salinity on these better performing genotypes could, perhaps, mitigate the negative impacts of a change in salinity in a scenario of desalination in the Baltic Sea as projected by (Meier et al. 2006). The relation of salinity and development time in E. affinis is population specific and, therefore, likely a consequence of adaptation to local conditions (Devreker et al. 2007, 2012; Lee et al. 2003). Temperature and salinity are seemingly two master factors that control development time for E. affinis in the Baltic Sea.

Survival is an indicator to evaluate copepods tolerance to different environmental conditions. For the STHLM population, adult survival was about $30 \%$ higher at 6 PSU than at $2 \mathrm{PSU}$, an expected result considering that ambient salinity is about $6 \mathrm{PSU}$ for this population. In comparison, a $5{ }^{\circ} \mathrm{C}$ increase from 15 to $20{ }^{\circ} \mathrm{C}$ caused $20 \%$ decrease in survival from nauplii to adult (Table 3, Fig. 4a). We observed no interactive effect of temperature and salinity for survival, even though tolerance for low and high salinities has been found to decrease as temperature increase to a stressful level in other populations (Gonzalez and Bradley 1994; Kimmel and Bradley 2001; Nagaraj 1992; Roddie et al. 1984). In the Baltic Sea, highest abundances of E. affinis are found at temperatures around 15 and $20^{\circ} \mathrm{C}$, e.g., in the Baltic Proper (Diekmann et al. 2012; Hernroth and Ackefors 1979). The STHLM population revealed to be sensitive to low salinity during nauplii stages but not during copepodid stages, so the effect of salinity on adult survival is largely an effect of nauplii mortality.

For the GOR population, survival was higher in ambient (5 PSU) salinity than in low salinity (0.5 PSU) and increased even further when salinity reached well above ambient conditions (10 and 15 PSU), it is not uncommon that populations perform better in conditions other than their native (Kawecki and Ebert 2004). In addition, perhaps, this is an indication of that brackish water bodies such as the Baltic Sea are marginal habitats, and that populations here live under a constant salinity compromise but also under a more relaxed competition from truly fresh or marine species that cannot tolerate these conditions. For the GOR population, survival was lower in the copepodid stages and higher in the nauplii stages (Fig. 4b) at 0.5 PSU, which is where brackish water transcends into freshwater (Remane and Schlieper 1972). Lee and Petersen (2002) found a similar pattern with lower copepodid survival due to low salinity for a North American population. Our results show opposing patterns for the STHLM and GOR populations. For individuals in the STHLM population, mortality happens mainly during their naupliar stage due 
to low salinity, whereas for individuals in the GOR population, mortality is higher during their copepodid stage. The previous studies of E. affinis populations from the Seine estuary and Chesapeake Bay have shown that mortality regardless of temperature and salinity treatment is highest in the late naupliar and early copepodid stages (Devreker et al. 2007, 2012).

\section{Conclusion}

In this study, we show that Baltic Sea E. affinis populations are sensitive to lower salinities than those that they are exposed to in their present environment. The low salinity treatments used in this study are in the range of what can be found in some areas of the Baltic Sea and of what can be expected by the end of this century at the locations where our populations were sampled (Meier et al. 2006). Our results clearly show that in lower salinities, hatching success, development time, and survival are negatively affected. Furthermore, we found a uniform response of individual genotypes to salinity, where all had faster development and higher survival when salinity increased. Our results suggest that Baltic Sea E. affinis likely could persist desalination down to almost freshwater conditions, however, with a significant reduction in fitness, which may compromise their competitive ability under future changing environmental conditions.

Acknowledgements We thank Nina Dagberg, Siv Huseby, Marilyn Kalaus, and Henn Ojaveer for field collection of zooplankton. This is a contribution to the BONUS BIO-C3 project and was supported by BONUS (Art 185), funded jointly by the EU and the Swedish Research Council FORMAS.

Funding This is a contribution to the BONUS BIO-C 3 project and was supported by BONUS (Art 185), funded jointly by the EU and the Swedish Research Council FORMAS.

\section{Compliance with ethical standards}

Conflict of interest We declare that there are no conflict of interest: Konrad Karlsson declares he has no conflict of interest, Simona Puiac declares she has no conflict of interest, and Monika Winder declares she has no conflict of interest.

Human or animal rights This study includes the use of invertebrate Crustaceans; all applicable international, national, and institutional guidelines for the care and use of animals were followed.

Open Access This article is distributed under the terms of the Creative Commons Attribution 4.0 International License (http://creativecomm ons.org/licenses/by/4.0/), which permits unrestricted use, distribution, and reproduction in any medium, provided you give appropriate credit to the original author(s) and the source, provide a link to the Creative Commons license, and indicate if changes were made.

\section{References}

Allan JD (1976) Life history patterns in zooplankton. Am Nat 110:165-180

Avery DE, Dam HG (2007) Newly discovered reproductive phenotypes of a marine copepod reveal the costs and advantages of resistance to a toxic dinoflagellate. Limnol Oceanogr 52:2099-2108

Ban S (1994) Effect of temperature and food concentration on postembryonic development, egg production and adult body size of calanoid copepod Eurytemora affinis. J Plankton Res 16:721-735

Bates D, Machler M, Bolker BM, Walker SC (2015) Fitting linear mixed-effects models using lme4. J Stat Softw 67:1-48

Beyrend-Dur D, Souissi S, Devreker D, Winkler G, Hwang J-S (2009) Life cycle traits of two transatlantic populations of Eurytemora affinis (Copepoda: Calanoida): salinity effects. J Plankton Res 31:713-728

Blaxter JH, Douglas B, Tyler PA, Mauchline J (1998) The biology of calanoid copepods, vol 33. Academic Press, Cambridge

Bolker BM, Brooks ME, Clark CJ, Geange SW, Poulsen JR, Stevens MHH, White J-SS (2009) Generalized linear mixed models: a practical guide for ecology and evolution. Trends Ecol Evol 24:127-135

Bradley B (1986) Genetic expression of temperature tolerance in the copepod Eurytemora affinis in different salinity and temperature environments. Mar Biol 91:561-565

Core Team R (2016) R: a language and environment for statistical computing. R Foundation for Statistical Computing, Vienna

Dam HG (2013) Evolutionary adaptation of marine zooplankton to global change. Ann Rev Mar Sci 5(5):349-370. https://doi. org/10.1146/annurev-marine-121211-172229

Davis MB, Shaw RG (2001) Range shifts and adaptive responses to quaternary climate change. Science 292:673-679. https://doi. org/10.1126/science.292.5517.673

Devreker D, Souissi S, Seuront L (2004) Development and mortality of the first naupliar stages of Eurytemora affinis (Copepoda, Calanoida) under different conditions of salinity and temperature. J Exp Mar Biol Ecol 303:31-46

Devreker D, Souissi S, Forget-Leray J, Leboulenger F (2007) Effects of salinity and temperature on the post-embryonic development of Eurytemora affinis (Copepoda; Calanoida) from the Seine estuary: a laboratory study. J Plankton Res 29:i117-i133

Devreker D, Souissi S, Winkler G, Forget-Leray J, Leboulenger F (2009) Effects of salinity, temperature and individual variability on the reproduction of Eurytemora affinis (Copepoda; Calanoida) from the Seine estuary: a laboratory study. J Exp Mar Biol Ecol 368:113-123

Devreker D, Pierson JJ, Souissi S, Kimmel DG, Roman MR (2012) An experimental approach to estimate egg production and development rate of the calanoid copepod Eurytemora affinis in Chesapeake Bay, USA. J Exp Mar Biol Ecol 416:72-83

Diekmann ABS, Clemmesen C, John MAS, Paulsen M, Peck MA (2012) Environmental cues and constraints affecting the seasonality of dominant calanoid copepods in brackish, coastal waters: a case study of Acartia, Temora and Eurytemora species in the south-west Baltic. Mar Biol 159:2399-2414

Engqvist L (2005) The mistreatment of covariate interaction terms in linear model analyses of behavioural and evolutionary ecology studies. Anim Behav 70:967-971. https://doi.org/10.1016/j.anbe hav.2005.01.016

Escaravage V, Soetaert K (1995) Secondary production of the brackish copepod communities and their contribution to the carbon fluxes in the Westerschelde estuary (The Netherlands). Hydrobiologia 311:103-114

Falconer DS, Mackay TFC (1996) Introduction to quantitative genetics. Longman, London 
Fox J (2003) Effect displays in R for generalised linear models. J Stat Softw 8:1-27

Fox J, Weisberg S (2011) An R companion to applied regression, 2nd edn. Sage, Thousand Oaks

Gasparini S, Castel J, Irigoien X (1999) Impact of suspended particulate matter on egg production of the estuarine copepod, Eurytemora affinis. J Mar Syst 22:195-205

Gillooly JF, Brown JH, West GB, Savage VM, Charnov EL (2001) Effects of size and temperature on metabolic rate. Science 293:2248-2251

Gillooly JF, Charnov EL, West GB, Savage VM, Brown JH (2002) Effects of size and temperature on developmental time. Nature 417:70-73

Gonzalez CR, Bradley BP (1994) Salinity stress proteins in Eurytemora affinis. In: Ferrari FD, Bradley BP (eds) Ecology and morphology of copepods. Springer, Netherlands, pp 461-468

Guillard RR, Ryther JH (1962) Studies of marine planktonic diatoms: I. Cyclotella Nana Hustedt, and Detonula Confervacea (CLEVE) Gran. Can J Microbiol 8:229-239

Heinle D, Flemer D (1975) Carbon requirements of a population of the estuarine copepod Eurytemora affinis. Mar Biol 31:235-247

Hernroth L, Ackefors H (1979) The zooplankton of the Baltic proper: a long-term investigation of the fauna, its biology and ecology. Swed Board Fish Inst Mar Res 2:60

Hirche H-J (1992) Egg production of Eurytemora affinis-effect of k-strategy. Estuar Coast Shelf Sci 35:395-407

Holliland PB, Ahlbeck I, Westlund E, Hansson S (2012) Ontogenetic and seasonal changes in diel vertical migration amplitude of the calanoid copepods Eurytemora affinis and Acartia spp. in a coastal area of the northern Baltic proper. J Plankton Res 34:298-307. https://doi.org/10.1093/plankt/fbs001

Holste L, Peck MA (2006) The effects of temperature and salinity on egg production and hatching success of Baltic Acartia tonsa (Copepoda: Calanoida): a laboratory investigation. Mar Biol 148:1061-1070. https://doi.org/10.1007/s00227-005-0132-0

Horne CR, Hirst AG, Atkinson D, Neves A, Kiørboe T (2016) A global synthesis of seasonal temperature-size responses in copepods. Global Ecol Biogeogr 25:988-999

Huntley ME, Lopez MD (1992) Temperature-dependent production of marine copepods: a global synthesis. Am Nat 140:201-242

Katona SK (1971) The developmental stages of Eurytemora affinis (Poppe, 1880) (Copepoda, Calanoida) raised in laboratory cultures, including a comparison with the larvae of Eurytemora americana Williams, 1906, and Eurytemora herdmani Thompson \& Scott, 1897. Crustaceana 21:5-20

Kawecki TJ, Ebert D (2004) Conceptual issues in local adaptation. Ecol Lett 7:1225-1241

Kimmel DG, Bradley BP (2001) Specific protein responses in the calanoid copepod Eurytemora affinis (Poppe, 1880) to salinity and temperature variation. J Exp Mar Biol Ecol 266:135-149

Lance J (1963) The salinity tolerance of some estuarine planktonic copepods. Limnol Oceanogr 8:440-449

Laprise R, Dodson JJ (1994) Environmental variability as a factor controlling spatial patterns in distribution and species diversity of zooplankton in the St. Lawrence Estuary. Mar Ecol Prog Ser 107:67

Lee CE, Petersen CH (2002) Genotype-by-environment interaction for salinity tolerance in the freshwater-invading copepod Eurytemora affinis. Physiol Biochem Zool 75:335-344. https://doi.org/10.1086 /343138

Lee CE, Petersen CH (2003) Effects of developmental acclimation on adult salinity tolerance in the freshwater-invading copepod Eurytemora affinis. Physiol Biochem Zool 76:296-301

Lee CE, Remfert JL, Gelembiuk GW (2003) Evolution of physiological tolerance and performance during freshwater invasions. Integr Comp Biol 43:439-449. https://doi.org/10.1093/icb/43.3.439
Lee CE, Remfert JL, Chang YM (2007) Response to selection and evolvability of invasive populations. Genetica 129:179-192. http s://doi.org/10.1007/s10709-006-9013-9

Lehmann A, Getzlaff K, Harlaß J (2011) Detailed assessment of climate variability of the Baltic Sea area for the period 1958-2009. Clim Res 46:185-196

Mclaren IA (1963) Effects of temperature on growth of zooplankton, and the adaptive value of vertical migration. J Fish Res Board Can 20:685-727

Meier H, Kjellström E, Graham L (2006) Estimating uncertainties of projected Baltic Sea salinity in the late 21 st century. Geophys Res Lett 33:L15705

Meunier CL, Boersma M, Wiltshire KH, Malzahn AM (2016) Zooplankton eat what they need: copepod selective feeding and potential consequences for marine systems. Oikos 125:50-58

Möllmann C, Köster FW (2002) Population dynamics of calanoid copepods and the implications of their predation by clupeid fish in the Central Baltic Sea. J Plankton Res 24:959-978

Nagaraj M (1988) Combined effects of temperature and salinity on the complete development of Eurytemora velox (Crustacea: Calanoidea). Mar Biol 99:353-358

Nagaraj M (1992) Combined effects of temperature and salinity on the development of the copepod Eurytemora affinis. Aquaculture 103:65-71

Parmesan C (2006) Ecological and evolutionary responses to recent climate change. Annu Rev Ecol Evol Syst 37:637-669. https:// doi.org/10.1146/annurev.ecolsys.37.091305.110100

Peitsch A, Köpcke B, Bernát N (2000) Long-term investigation of the distribution of Eurytemora affinis (Calanoida; Copepoda) in the Elbe Estuary. Limnol Ecol Manag Inland Waters 30:175-182

Remane A, Schlieper C (1972) Biology of brackish water. Schweizerbart Science Publishers, Stuttgart

Roddie B, Leakey R, Berry A (1984) Salinity-temperature tolerance and osmoregulation in Eurytemora affinis (Poppe)(Copepoda: Calanoida) in relation to its distribution in the zooplankton of the upper reaches of the Forth estuary. J Exp Mar Biol Ecol 79:191-211

Sanford E, Kelly MW (2011) Local adaptation in marine invertebrates. Ann Rev Mar Sci 3:509-535

Sarkar D (2008) Lattice: multivariate data visualization with $R$. Springer Science \& Business Media, New York

Schmitt FG, Devreker D, Dur G, Souissi S (2011) Direct evidence of tidally oriented behavior of the copepod Eurytemora affinis in the Seine estuary. Ecol Res 26:773-780

Stibor H et al (2004) Copepods act as a switch between alternative trophic cascades in marine pelagic food webs. Ecol Lett 7:321-328

Tomczak M, Niiranen S, Hjerne O, Blenckner T (2012) Ecosystem flow dynamics in the Baltic proper-using a multi-trophic dataset as a basis for food-web modelling. Ecol Model 230:123-147

van Someren Gréve H, Almeda R, Kiørboe T (2017) Motile behavior and predation risk in planktonic copepods. Limnol Oceanogr 62:1810-1824. https://doi.org/10.1002/lno.10535

Vuorinen I (1982) The effect of temperature on the rates of development of Eurytemora hirundoides (Nordqvist) in laboratory culture. In: Ann Zool Fenn, 1982. JSTOR, pp 129-134

Wickham H (2016) ggplot2: elegant graphics for data analysis. Springer, New York

Winkler G, Dodson JJ, Bertrand N, Thivierge D, Vincent WF (2003) Trophic coupling across the St. Lawrence River estuarine transition zone. Mar Ecol Prog Ser 251:59-73 